\title{
A serological survey of brucellosis in wild ungulate species from five game parks in Zimbabwe
}

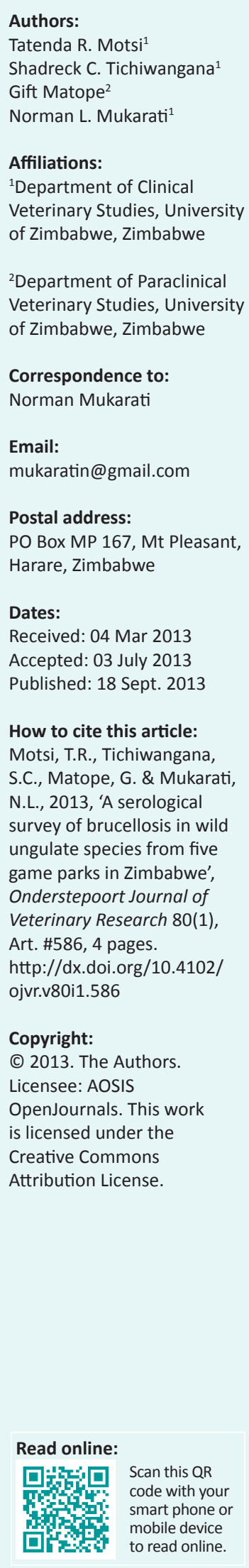

A retrospective serosurvey was carried out between 2009 and 2012 to detect antibodies to Brucella spp. in free-ranging African wildlife ungulates from five selected game parks in Zimbabwe. Samples were drawn from wildlife-livestock interface and non-interface areas in Zimbabwe. A total of 270 serum samples from four different species, namely African buffalo (Syncerus caffer) $(n=106)$, impala (Aepyceros melampus) $(n=72)$, black rhinoceros (Diceros bicornis) $(n=45)$ and white rhinoceros (Ceratotherium simum) $(n=47)$, were tested. The percentage of positive samples was $17.0 \%$ in buffalo $(18 / 106 ; 95 \%$ CI: $9.72 \%-24.1 \%)$ and $1.4 \%$ in impala $(1 / 72 ; 95 \%$ CI: $0 \%-4.2 \%)$. No antibodies to Brucella spp. were detected in the two rhinoceros species. The difference in the percentage of seropositive cases between buffalo and impala was significant $(p<0.05)$. Seropositivity to Brucella spp. was higher $(19.1 \%)$ in adult buffalo compared with juveniles and sub-adults younger than six years (5.9\%). Further, seropositivity was marginally higher $(20.4 \%)$ in animals from wildlife-livestock interface areas than in those from non-interface areas $(13.45 \%$; OR $=1.45)$ although the difference was not statistically significant. The study showed that brucellosis could be more widespread in buffalo and may circulate in this species independently in the absence of contact with cattle, whilst rhinoceros may be considered less susceptible to brucellosis. The role of the wildlifelivestock interface in the epidemiology of brucellosis in wildlife and livestock is probably overstated but needs to be explored further.

\section{Introduction}

Brucellosis is a disease of both economic and public health importance in many countries in subSaharan Africa, where it is endemic, especially in cattle. In Zimbabwe, bovine brucellosis was first confirmed in 1913 (Bevan 1931). The disease was later gazetted as 'notifiable', which allowed monitored control through compulsory vaccination and implementation of the accreditation scheme in commercial farms. Consequently, the disease was brought under control in some farms (Madsen 1989), but an upsurge of the disease has recently been noted following the economic depression that has affected the country since 2000 (Matope et al. 2010).

Serological evidence of brucellosis in free-living wild animal species was first documented in the 1960s in sub-Saharan African countries, including South Africa (De Vos \& Van Niekerk 1969), Uganda (Guilbride et al. 1962), Tanzania (Sachs 1966) and Zimbabwe (Condy \& Vickers 1972). Several free-living wild animal species, such as the African buffalo (Syncerus caffer), hippopotamus (Hippopotamus amphibius), impala (Aepyceros melampus), blue wildebeest (Connochaetes taurinus), zebra (Equus burchelli) and eland (Tragelaphus oryx), have been consistently reported to be seropositive (Condy \& Vickers 1972; De Vos \& Van Niekerk 1969; Herr \& Marshall 1981; Madsen \& Anderson 1995; Sachs 1966; Waghela \& Karstad 1986), indicating possible persistent foci of infection in these animals. However, it is noteworthy that Brucella seropositivity is yet to be reported in the black rhinoceros (Diceros bicornis) and the white rhinoceros (Ceratotherium simum). Whether these can be considered susceptible species for brucellosis needs to be explored further.

Although Brucella abortus biovar 1 and Brucella melitensis have been isolated from buffalo and waterbuck (Kobus ellipsiprymnus) (Condy \& Vickers 1969; Gradwell et al. 1977; Kaliner \& Staak 1973), and impala (Schiemann \& Staak 1971), respectively, their clinical significance in wildlife is not yet clear. Anecdotal evidence indicated the presence of hygromata, orchitis and abortion in buffalo and waterbuck (Kaliner \& Staak 1973; Thornton 1976), which closely resembled symptoms of brucellosis in livestock.

The importance of brucellosis in wildlife in relation to the risk of transmission to domestic animals has been debated widely in literature (Bishop, Bosman \& Herr 1994). The general argument appears to be that the risk of transmission of brucellosis to domestic animals is low due to infrequent contact (Madsen \& Anderson 1995). However, the factors influencing the epidemiology of the disease in wildlife have not been studied in detail. In some regions, the disease is believed to 
be re-emerging, particularly in the wildlife-domestic animal interface areas (Bengis \& Erasmus 1988; Kock 2005) and thus its presence and host range in wildlife species need to be determined. The management of wildlife in Zimbabwe has changed dramatically over the past two decades to bring about intensification of interaction of animal species at the interface. This was brought about mainly by the country's agrarian reform programme, which started in 2000, and the creation of large landscape mosaics of wild animals, domestic livestock and humans under the transfrontier conservation area (TFCA) initiatives. In addition, surveillance for animal diseases, including brucellosis, in wildlife has been lacking in the past decade. Therefore, the objective of this study was to estimate prevalence of antibodies to Brucella spp. in freeliving wildlife ungulates, especially buffalo and rhinoceros, from protected areas with and without known interface areas with domestic livestock.

\section{Materials and methods \\ Study areas}

The study was conducted in five game parks, which were randomly selected from protected national parks (Gonarezhou and Hwange), safari areas (Wild Horizons) and private wildlife sanctuaries (Malilangwe Conservancy and Save Valley Conservancy), located mainly in the north-western and south-eastern parts of Zimbabwe (Figure 1). These game parks were further categorised into wildlife-domestic animal interface areas (Gonarezhou National Park, Save Valley Conservancy and Wild Horizons) and non-interface areas (Hwange National Park and Malilangwe Conservancy).

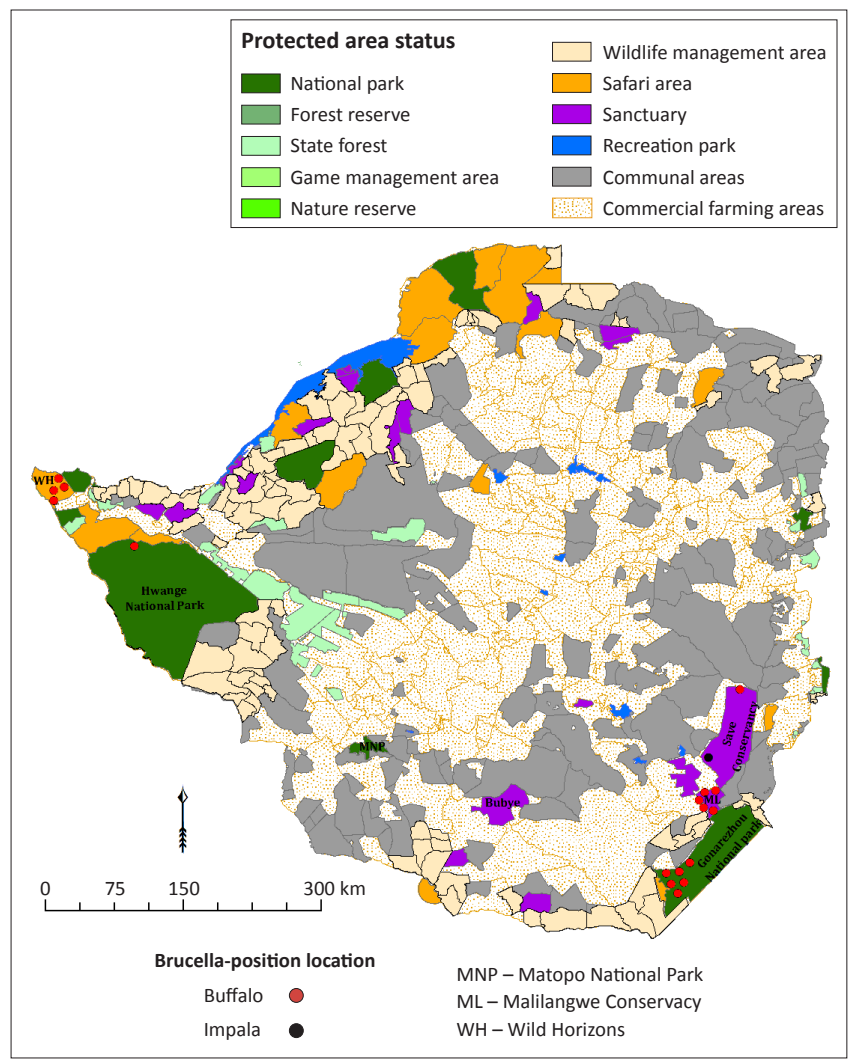

FIGURE 1: Map of Zimbabwe showing the land use classification, study sites and sites from which Brucella-positive samples were obtained.
Interface areas were described as areas where contact between wildlife and cattle from adjacent communal areas was possible, whereas non-interface areas were described as areas where no cattle were present and game were separated from domestic animals by a fence. The wildlife-domestic animal interface has been defined as either direct, physical sharing of the same space at the same time or indirect contact through soil, forage and water with which another animal had recently been in contact with and where bodily secretions have been left (Bengis, Kock \& Fischer 2002). For example, in the Gonarezhou National Park cattle gain access to the park through broken fences in search of grazing and water (Gomo et al. 2012), whilst the Save Valley Conservancy is surrounded by both communal and commercial cattle farms where contact is possible. Wild Horizons is a safari area that is uncultivated and unfenced and contact with cattle is possible in some areas, but this area is mainly situated in a tsetse fly zone, which restricts cattle rearing (Madsen \& Anderson 1995).

\section{Sample collection and ethical considerations}

Serum samples from buffalo $(n=106)$, black rhinoceros $(n=45)$, white rhinoceros $(n=47)$ and impala $(n=72)$ from the different study areas were collected by jugular venopuncture during routine disease surveillance activities by the Wildlife Unit of the Department of Veterinary Services between 2009 and 2012. The ethical approval for collection of these samples was obtained from the Directorate of Veterinary Services and standard operating procedures were followed for tracking, darting (anaesthetising), bleeding and post-operative care of the animals to minimise unnecessary stress and injury to the animals (Kock, Meltzer \& Burroughs 2007; McKenzie 1993).

\section{Laboratory tests}

The laboratory tests were conducted in the Serology Laboratory of the Central Veterinary Laboratory in Harare. All the sera, stored at $-20{ }^{\circ} \mathrm{C}$, were thawed overnight at $4{ }^{\circ} \mathrm{C}$ prior to testing. Sera were tested for antibodies to smooth Brucella species (B. abortus, B. melitensis and Brucella suis) by means of the Rose Bengal test (RBT) and the complement fixation test (CFT) using standardised B. abortus antigens obtained from the Onderstepoort Veterinary Institute, South Africa. Both tests were performed essentially as for bovines as described by Alton and co-workers (Alton et al. 1988) as no other specific tests have been validated for use in wildlife (Condy \& Vickers 1972; Madsen \& Anderson 1995). The positive control sera were obtained from the Onderstepoort Veterinary Institute, whilst the negative control sera were from the Central Veterinary Laboratory, Harare. All the reagents and test sera were brought to room temperature $\left(24{ }^{\circ} \mathrm{C}-26{ }^{\circ} \mathrm{C}\right)$ before testing. Tests were performed in 80 round-bottomed microtitre plates (Nunc plates, Denmark). Aliquots of $25 \mu \mathrm{L}$ test and control sera were mixed with approximately equal volumes of antigen and the plates were shaken gently on an orbital shaker for 5 minutes. All the sera testing positive with the RBT were further tested using the CFT. Owing to validation data for these tests not being available, the results were interpreted as for non-vaccinated cattle (Brinley-Morgan 1967). 


\section{Data analysis}

Data analysis was performed using Stata Version SE 11.0 for Windows (Stata Corp., College Station, Texas). Individual animals were classified as Brucella positive if they tested positive on both the RBT and the CFT with titres of $>20$ IU as suggested by the World Organisation for Animal Health (OIE 2009). The mean number of seropositive animals and the $95 \%$ confidence intervals of the means were calculated by considering the number of positive and total samples tested in the different animal species, age group (sub-adult [ $<3$ years] vs adult [ $>3$ years]), sex, game park and type of interface (interface vs non-interface). A simple proportion test was used to assess differences in prevalence between variables and values of $p<0.05$ were regarded as significant.

\section{Results and discussion}

We investigated the presence of antibodies to smooth Brucella spp. in African buffalo, black rhinoceros, white rhinoceros and impala from selected interface and non-interface game parks in Zimbabwe. The study showed that seropositive reactors were present in buffalo (17.0\%) and impala (1.4\%), but not in either black or white rhinoceros (Table 1). The interpretation of test results from different animal species poses problems as these serological tests have not been validated for use in wild animals. However, despite lack of test validation, antibodies to Brucella spp. have been detected using similar testing regimens in buffalo, impala, eland, zebra, giraffe (Giraffa camelopardalis) and other species in Zimbabwe (Condy \& Vickers 1972; Madsen \& Anderson 1995) and elsewhere in Africa (Alexander et al. 2012; Bengis et al. 2004; Gradwell et al. 1977; Hamblin et al. 1990; Herr \& Marshall 1981; Sachs 1966). This is further supported by isolation of Brucella spp. from some of these animal species, where clinical features of brucellosis similar to those seen in domestic animals were observed (Condy \& Vickers 1969; Kaliner \& Staak 1973; Schiemann \& Staak 1971). Therefore, the suggestion that brucellosis may be more prevalent in aggregative wild animals such as buffalo and possibly impala cannot be ruled out. Although this was the first large-scale study of brucellosis in both the black and the white rhinoceros, the failure to detect Brucella antibodies highlighted the need not only to validate the serological tests in these species but also to ascertain their susceptibility, and hence ability to seroconvert, if exposed to Brucella spp. Alternatively, for unknown host-specific reasons, the rhinoceros could be considered less susceptible to brucellosis given that the disease has not been reported in these species in literature (AQIS 1999).

The observed seroprevalence data for age and sex (Table 2) were consistent with the biology of Brucella spp. in cattle in that the risk of infection is independent of sex but tends to increase with sexual maturity of animals (Gul \& Khan 2007; Muma et al. 2006). Brucellosis has been associated with hygromas and orchitis in some free-ranging buffalo and other wild animals, but abortions are believed to be infrequent (De Vos \& Van Niekerk 1969; Thornton 1976), notwithstanding the isolation of B. abortus from pregnant uteri (Herr \& Marshall 1981). However, the clinical importance of brucellosis in wildlife requires further study.

Based on the results shown in Table 2, this study further provided support that brucellosis in the tested buffalo appears to exist in areas where no previous cattle contact was demonstrated (Condy \& Vickers 1972). This indicates that infection may circulate within the species independently. Consequently, it is difficult to determine the sources of infection for these animals although some studies suggested that they appear to have originated from domestic animals (Bishop et al. 1994). Although the general consensus is that wild animals with limited contact with cattle are unlikely to be important sources of infection for domestic livestock (Madsen \& Anderson 1995), finding seropositive buffalo in the interface areas may indicate the presence of potential reservoirs of infection for both cattle and humans (Bengis et al. 2004; Godfroid et al. 2011). However, the role of wildlife-domestic animal interaction at interface areas in the transmission of brucellosis across animal species is contentious and may possibly be overstated. The evidence here supports the hypothesis that intraherd and interspecies transmission rates are low in and between livestock and wildlife, and that the ruminant wildlife-livestock interface is limited in spatial and temporal extent, resulting in low prevalence if wildlife is indeed a spillover host for Brucella infection originating from livestock. In our view, and as suggested by Condy and Vickers (1972), detailed studies

TABLE 1: The distribution of the Brucella seropositive wildlife ungulates from selected game parks in Zimbabwe.

\begin{tabular}{|c|c|c|c|c|}
\hline Animal species & Number tested & Number positive & $\%$ & Confidence Interval (95\%) \\
\hline Buffalo (Syncerus caffer) & 106 & 18 & 17.0 & $9.7-24.2 \dagger$ \\
\hline Impala (Aepyceros melampus) & 72 & 1 & 1.4 & $0.0-4.2 \dagger$ \\
\hline Black rhinoceros (Diceros bicornis) & 45 & 0 & 0.0 & - \\
\hline White rhinoceros (Ceratotherium simum) & 47 & 0 & 0.0 & - \\
\hline
\end{tabular}

$\dagger$, Seroprevalence of brucellosis in buffaloes was significantly different from that of impala at $p<0.05$

TABLE 2: The distribution of the Brucella seropositive buffalo (Syncerus caffer) from selected game parks in Zimbabwe.

\begin{tabular}{|c|c|c|c|c|c|c|c|c|c|c|c|}
\hline \multirow[t]{2}{*}{ Variable } & \multicolumn{5}{|c|}{ Origin } & \multicolumn{2}{|c|}{ Type of interface } & \multicolumn{2}{|l|}{ Age group } & \multicolumn{2}{|c|}{ Sex } \\
\hline & & & & & & Non-interface & Interface & Juvenile or sub-adult & Adult & Female & Male \\
\hline Level & 1 & 2 & 3 & 4 & 5 & - & - & - & - & - & - \\
\hline Number tested & 21 & 18 & 34 & 13 & 20 & 52 & 54 & 17 & 89 & 76 & 30 \\
\hline Number positive & 6 & 2 & 5 & 1 & 4 & 7 & 11 & 1 & 17 & 16 & 2 \\
\hline Percentage & 28.6 & 11.1 & 14.7 & 7.7 & 20.0 & 13. 4 & 20.4 & 5.9 & 19.1 & 21.1 & 6.7 \\
\hline Confidence interval (95\%) & $8.5-48.6$ & $0.0-26.2$ & $2.5-26.9$ & $0.0-22.9$ & $1.8-38.2$ & $4.0-23.0$ & $9.4-31.3$ & $0.0-17.5$ & $10.8-27.4$ & $11.7-30.4$ & $0.0-15.9$ \\
\hline
\end{tabular}


on isolation and molecular characterisation of Brucella spp. should be performed to determine the possibility of pathogen sharing at wildlife-domestic animal interface areas as not much advances have been made since brucellosis was first documented in wildlife.

The definition and hence the categorisation of interface areas are subject to different categorisations by different individuals. As an example, the Malilangwe Conservancy in the southeastern lowveld of Zimbabwe was classified as a non-interface area in our study on account of it being securely fenced. However, the Malilangwe Conservancy shares boundaries with adjacent communal lands where cattle graze alongside the conservancy fence, thus constituting a linear interface interaction of species. The high proportion of seropositive reactors in buffalo in the conservancy $(14.7 \%, n=34)$ may similarly be attributed to contact with domestic livestock.

\section{Conclusion}

Until a systematic epidemiological study regarding brucellosis has been conducted, including molecular characterisation of the bacterial isolates, the respective roles of domestic livestock and wildlife in the maintenance and propagation of the disease will continue to be contentious.

\section{Acknowledgements}

The authors would like to acknowledge Dr C. Foggin and staff at the Wildlife Unit, Division of Veterinary Field Services, Department of Animal Production and Veterinary Services, who provided the samples and assisted in the selection of study areas, and Dr P.V. Makaya and staff at the Central Veterinary Laboratory, Division of Veterinary Technical Services, Department of Animal Production and Veterinary Services who provided facilities for the laboratory testing of the samples. Finally, the authors gratefully acknowledge the critique of this manuscript by Dr D.M. Pfukenyi, Faculty of Veterinary Science, University of Zimbabwe.

\section{Competing interests}

The authors declare that they have no financial or personal relationship(s) that may have inappropriately influenced them in writing this article.

\section{Authors' contributions}

T.R.M. and S.C.T. (both University of Zimbabwe) performed the laboratory testing of samples and compiled the raw data. N.L.M. (University of Zimbabwe) designed the project, organised testing of samples and wrote the manuscript. G.M. (University of Zimbabwe) was responsible for analysis of the results and contributed to the writing of the manuscript.

\section{References}

Alexander, K.A., Blackburn, J.K., Vandewalle, M.E., Pesapane, R., Baipoledi, E.K. \& Elzer P.H., 2012, 'Buffalo, bush meat, and the zoonotic threat of brucellosis in Botswana', PLOS ONE 7(3), 32842, viewed 20 March 2012, from http://www.plosone.org/ article/info\%3Adoi/10.1371/journal.pone.0032842

Alton, G., Jones, L.M., Angus R.D. \& Verger J.M., 1988, Techniques for the brucellosis Laboratory, Institut National de la Recherche Agronomique, Paris.
AQIS, 1999, 'Review of conditions for the importation of rhinoceros from South Africa', final report, Australian Quarantine and Inspection Service, Canberra.

Bengis, R.G. \& Erasmus, J.M., 1988, 'Wildlife diseases in South Africa: A review', Revue Scientifique et Technique de l'OIE 7(4), 807-821.

Bengis, R.G., Kock, R.A. \& Fischer, J., 2002, 'Infectious animal diseases: The wildlife/ livestock interface', Revue Scientifique et Technique de l'OIE 21(1), 53-65.

Bengis, R.G., Leighton, F.A., Fischer, J.R., Artois, M., Mörner, T. \& Tate, C.M., 2004, 'The role of wildlife in emerging and re-emerging zoonoses', Revue Scientifique et Technique de I'OIE 23(2), 497-511.

Bevan, L.E.W., 1931, 'Notes on a case of Rhodesian undulant fever', Transactions of the Royal Society for Tropical Medicine and Hygiene 24, 93-95. http://dx.doi. org/10.1016/S0035-9203(30)90746-8

Bishop, G.C., Bosman, P.P. \& Herr, S., 1994, 'Bovine brucellosis', in J.A.W. Coetzer, G.R. Thompson \& R.C. Tustin (eds.), Infectious diseases of livestock with special reference to Southern Africa, Volume II, Oxford University Press, London, $\mathrm{pp}$ 1053-1066.

Brinley-Morgan, W.J. 1967, 'The serological diagnosis of bovine brucellosis', Veterinary Record 80, 612-620. http://dx.doi.org/10.1136/vr.80.21.612

Condy, J.B. \& Vickers, D.B., 1969, 'The isolation of Brucella abortus from a Waterbuck', Veterinary Record 85, 200.

Condy, J.B. \& Vickers, D.B., 1972, 'Brucellosis in Rhodesian wildlife' Journal of the South African Veterinary Medicine Association 43, 175-179

De Vos, V. \& Van Niekerk, C.A.W.J., 1969, 'Brucellosis in the Kruger National Park', Journal of the South African Veterinary Medical Association 40(3), 331-334.

Godfroid, J., Scholzc, H.C., Barbierd, T., Nicolasd, C., Wattiaue, P., Fretine, D. et al., 2011, 'Brucellosis at the animal/ecosystem/human interface at the beginning of the 21st century', Preventive Veterinary Medicine 102(2), 118-131. http://dx.doi. org/10.1016/j.prevetmed.2011.04.007, PMid:21571380

Gomo, C., De Garine-Wichatitsk, M., Caron, A. \& Pfukenyi, M.D., 2012, 'Survey of brucellosis at the wildlife-livestock interface on the Zimbabwean side of the Great Limpopo Transfrontier Conservation Area', Tropical Animal Health Production 44(1) 77-85. http://dx.doi.org/10.1007/s11250-011-9890-5, PMid:21643664

Gradwell, D.V., Schutte, A.P., Van Niekerk, C.A.W.J. \& Roux, D.J., 1977, 'The isolation of Brucella abortus biotype 1 from African buffalo in the Kruger National Park', Journal of the South African Veterinary Association 48(1), 41-43. PMid:406393

Guilbride, P.D.L., Coyle, T.J., McNulty, E.G., Barber, L. \& Lomax, G.D., 1962, 'Some pathogenic agents found in hippopotamus in Uganda', Journal of Comparative Pathology and Therapeutics 72, 137-141. http://dx.doi.org/10.1016/S03681742(62)80016-2

Gul, S.T. \& Khan, A., 2007, 'Epidemiology and epizootology of brucellosis: A review', Pakistan Veterinary Journal 27,145-151.

Hamblin, C., Anderson, E.C., Jago, M., Mlengeya, T. \& Hirji, K., 1990, 'Antibodies to some pathogenic agents in free-living wild species in Tanzania', Epidemiology and Infection 105(3) 585-594. http://dx.doi.org/10.1017/S0950268800048226, PMid:2123458, PMCid:PMC2271831

Herr, S. \& Marshall, C., 1981, 'Brucellosis in free-living African buffalo (Syncerus caffer): A serological survey', Onderstepoort Journal of Veterinary Research 48, 133-134. PMid:7335327

Kaliner, G. \& Staak, C., 1973, 'A case of orchitis caused by Brucella abortus in an African buffalo', Journal of Wildlife Diseases 9, 251-253.

Kock, M.D, Meltzer, D. \& Burroughs, R. (eds.), 2007, Chemical and physical restraint of wild animals: A training and field manual, International Wildlife Veterinary Services, Greyton (South Africa)/California, USA.

Kock, R. A., 2005, "What is this infamous "wildlife/livestock disease interface"? A review of current knowledge for the African continent', in S. Osofsky, S. Cleveland,
W.B. Karesh, M.D. Kock, P.J. Nyhus \& L. Starr (eds.), Conservation and Development W.B. Karesh, M.D. Kock, P.J. Nyhus \& L. Starr (eds.), Conservation and Development
Interventions at the Wildlife/Livestock Interface: Implications for Wildlife, Livestock Interventions at the Wildlife/Livestock Interface: Implication
and Human Health, pp. 1-14, IUCN, Gland/Cambridge.

Madsen, M., 1989, 'The current status of brucellosis in Zimbabwe', Zimbabwe Veterinary Journal 20, 133-145.

Madsen, M. \& Anderson, C., 1995, 'Serologic survey of Zimbabwean wildlife for brucellosis', Journal of Zoo and Wildlife Medicine 26(2), 240-245.

Matope, G., Makaya, P.V., Dhliwayo, S., Gadha, S., Madekurozwa, R.L. \& Pfukenyi, D.M., 2010, 'A retrospective study of brucellosis seroprevalence in commercial and smallholder cattle farms of Zimbabwe', Bulletin for Animal Health and Production in Africa 58, 326-333.

McKenzie, A.A. (ed.), 1993, The Capture and Care manual: Capture, care, accommodation and transportation of wild African animals, Wildlife Decision Support Services/ South African Veterinary Foundation, Lynnwood Ridge, Pretoria.

Muma, J.B., Samui, K.L., Siamdaala, V.M., Oloya, J., Matope, G., Omer, M.K. et al., 2006 'Prevalence of antibodies to Brucella spp. and individual risk factors in traditional cattle, goats and sheep reared in livestock-wildlife interface areas of Zambia', Tropical Animal Health and Production 38, 195-206. http://dx.doi.org/10.1007/ s11250-006-4320-9, PMid:16986767

OIE, 2009, 'Bovine brucellosis', in Manual of Diagnostic Tests and Vaccines for Terrestrial Animals, 6th edn., Office Internationale des Epizooties, Paris, viewed 20 March 2012, from http://www.oie.int/eng/normes/mmanual/2008/pdf/2.04.03_BOVINE BRUCELL.pdf

Sachs, R., 1966, 'Brucellosis in antelopes in Serengeti', Veterinary Record 79(26), 857-858. http://dx.doi.org/10.1136/vr.79.26.857, PMid:6009186

Schiemann, B. \& Staak, C., 1971, 'Brucella melitensis in impala', Veterinary Record 88, 344. http://dx.doi.org/10.1136/vr.88.13.344, PMid:5575513

Thornton, H., 1976, 'Unusual pathological conditions: Brucella hygromas in an eland (Tragelapus oryx)', Rhodesian Veterinary Journal 7, 64.

Waghela, S. \& Karstad, L., 1986, 'Antibodies to Brucella spp. among blue wildebeest and African buffalo in Kenya', Journal of Wildlife Diseases 22(2), 189-192. PMid:3712644 